\title{
A Focused Update on Tardive Dyskinesia
}

\author{
Pierre J. Blanchet
}

\begin{abstract}
Tardive dyskinesia (TD) is a delayed and potentially irreversible motor complication following chronic exposure to centrally acting dopamine receptor antagonists, mainly of the class of antipsychotics drugs. New generations of antipsychotic drugs reduced its mean prevalence to $20 \%$, but it continues to mar the drug experience and social integration in a significant fraction of patients. The underlying molecular cascade remains elusive, explaining in part why TD management is so often difficult. Protocol variations between experimental laboratories and inter-species differences in the biological response to antipsychotic drugs have added layers of complexity. The traditional dopamine $\mathrm{D}_{2}$ receptor supersensitivity hypothesis was revisited in an experimental nonhuman primate model. Findings in the striatum revealed a strong upregulation of $\mathrm{D}_{3}$, not $\mathrm{D}_{2}$, receptors specific to dyskinetic animals, and indirect evidence suggestive of a link between overactivation of glycogen synthase kinase- $3 \beta$ signaling and TD. New effective vesicular monoamine transporter type 2 inhibitors alleviating TD have been approved in the USA. They were integrated to an emerging stepwise treatment algorithm for troublesome TD, which also includes consideration for changes in the current antipsychotic drug regimen and recognition of potentially aggravating factors such as anticholinergic co-medications. These advances may benefit TD.
\end{abstract}

RÉSUMÉ: Une mise à jour au sujet de la dyskinésie tardive. La dyskinésie tardive (DT) est une complication motrice souvent irréversible survenant à distance de la mise en route d'un traitement chronique avec un antagoniste des récepteurs dopaminergiques du système nerveux central, en particulier de la classe des antipsychotiques. Les antipsychotiques modernes ont permis une réduction de sa prévalence moyenne à 20\%, mais elle continue de gâcher l'expérience du médicament et l'intégration sociale de trop nombreux patients. La méconnaissance de la cascade de signalisation moléculaire inductrice explique en partie les difficultés de sa prise en charge. Des variations dans les protocoles expérimentaux utilisés dans les laboratoires et des différences entre les espèces dans la réponse biologique à l'exposition antipsychotique ont contribué à gêner la découverte des mécanismes physiopathologiques. L'hypothèse d'une hypersensibilité des récepteurs dopaminergiques $\mathrm{D}_{2}$ dans cette condition a été réexaminée à l'aide d'un modèle expérimental chez le singe. Les trouvailles dans le striatum ont révélé une forte régulation à la hausse de la densité des récepteurs $\mathrm{D}_{3}$, pas $\mathrm{D}_{2}$, spécifique aux animaux dyskinétiques, et fourni des arguments indirects suggérant un lien entre une suractivation de la signalisation de la kinase GSK-3 $\beta$ et la DT. De nouveaux inhibiteurs du transporteur vésiculaire des monoamines de type 2 prouvés efficaces pour soulager la DT ont été approuvés aux Etats-Unis. Ils ont été intégrés aux efforts de développement d'un algorithme de soins pour la DT dérangeante, qui inclut un possible ajustement du traitement antipsychotique et le contrôle de facteurs potentiellement aggravants comme l'usage d'une comédication anticholinergique. Ces avancées pourraient contribuer à atténuer la DT.

Keywords: Tardive dyskinesia, Antipsychotic drugs, Dopamine D3 receptor, GSK-3, Striatum

doi:10.1017/cjn.2020.131

Can J Neurol Sci. 2020; 47: 747-755

\section{INTRODUCTION}

Tardive dyskinesia (TD) is a delayed and often irreversible motor complication resulting from long-term exposure to centrally acting dopamine $\mathrm{D}_{2}$ receptor blocking agents. Documented over 60 years ago, many consider it a legacy condition of an era when only potent (first generation) antipsychotic drugs were available. This attitude contributed in part to a stunning increase in label and off-label use of second-generation (so-called atypical) antipsychotic drugs with combined dopamine and serotonin $\left(\mathrm{D}_{2} / 5-\mathrm{HT}_{2 \mathrm{~A}}\right)$ blocking properties. Recent studies from different countries suggest that the TD landscape has changed appreciably since the advent of the atypical drugs, but long-term prevalence rates over $20 \%$ are still being reported. Thus, one can reasonably expect TD to remain on the radar screen in the foreseeable future. The enduring knowledge gap in pathophysiology greatly impeded the development of effective preventative and curative measures against TD, and the synthesis of novel antipsychotic drugs that would not trigger the molecular signaling defects leading to TD. Still, progress is being made in clarifying the modern epidemiology of TD, the neural circuitry involved, and the contribution of dopamine signaling confirmed by newer effective vesicular monoamine transporter type 2 (VMAT2) function inhibitors, which rekindled the interest about TD and enriched a practical management algorithm for the condition. This brief update will focus on these aspects. Further reading on the definition and recognition of the different tardive syndromes can be found elsewhere. ${ }^{1}$

From the Department of Stomatology, Faculty of Dental Medicine, University of Montreal, Montreal, Quebec, Canada; Department of Medicine, University of Montreal Hospital Centre (CHU Montreal), Montreal, Quebec, Canada; and Montreal Mental Health University Institute (IUSMM), Montreal, QC, Canada

Received May 4, 2020. Final Revisions Submitted June 4, 2020. Date of AcCeptance June 22, 2020.

Correspondence to: Pierre J. Blanchet, Faculty of Dental Medicine, University of Montreal, PO Box 6128, Succ. Centre-ville, Montreal, Quebec, Canada H3C 3J7. Email: pierre.j.blanchet@umontreal.ca

Presented in part at the parallel session "Active management of complex issues in movement disorders," Canadian Neurological Sciences Federation $54^{\text {th }}$ Congress, Montreal, Quebec, Canada, June 16, 2019. 


\section{EPIDEMIOLOGY AND Functional IMPAIRMENT}

Recent studies have contributed to shed light on the challenge of TD and its impact on quality of life. The reputed anosognosia of patients about TD and its lack of impact on quality of life have been called into question. In an online survey of a selected sample of patients with various psychiatric diagnoses, ${ }^{2}$ TD subjects had worse figures for health-related quality-of-life scores and social withdrawal than those without TD, and this was particularly true of those with schizophrenia, a surprising finding given that approximately $50 \%$ of subjects with schizophrenia have apparently no or low awareness of TD. ${ }^{3}$ In a cohort of 204 patients living with a schizophrenia spectrum disorder $(54 \%)$ or another psychiatric condition and TD, over $40 \%$ reported that their involuntary movements had at least some impact on their quality of life, and three-quarters felt self-conscious or embarrassed about these movements. ${ }^{4}$ In 110/204 patients with TD, an overlap was documented between the clinician-rated assessment of TD severity and the patient self-assessment. A recent review revealed a regrettable paucity of studies on the functional impairment and physical capacity limits related to the body distribution of TD. ${ }^{5}$ Impaired dexterity may compromise professional and domestic activities. Gait pattern and balance control are affected in up to $59 \%$ of those affected, in addition to speech and swallowing mechanisms. Severe oral pain and problems with teeth and/or dentures had also been reported previously. ${ }^{6}$ Severe TD is associated with social stigma and increased suicide rates. A bidirectional unexplained relationship has long been recognized between TD and cognitive impairment, ${ }^{5}$ perhaps suggesting that the signaling alterations and plastic changes underlying TD extend beyond the sensorimotor territory of the subcorticofrontal circuitry.

Contemporary epidemiological data generated from long-term prospective studies on the differential risk of TD with atypical antipsychotic drugs are beginning to emerge, not devoid of selection biases. They often recruit TD-free subjects not drugnaïve at baseline, who have been typically exposed to several typical antipsychotics previously. These individuals may be considered in a sensitized state promoting TD induction, or in a compensatory state effectively fending off drug sensitization. Within these limits, a large prospective study $(\mathrm{N}=352)$ conducted in Connecticut between 2000 and 2005 concluded that the incidence of TD with atypical drugs was similar to findings generated locally two decades ago during the era of conventional antipsychotic drug therapy. ${ }^{7} \mathrm{~A}$ recent meta-analysis cumulating 41 studies constituted a reality check for clinicians claiming that TD had vanished with modern drug therapy, reporting an overall mean prevalence of TD of $25.3 \%$, lower in those under current second-generation antipsychotic drugs $(20 \%)$ relative to those under first-generation drugs (30\%). ${ }^{8}$ In Caroff et al. [4], studies reporting on 352 participants never exposed to first-generation antipsychotics, including 80 children, prevalence of definite TD was determined to be $7.2 \%$, or $9.6 \%$ among the adult population, a favorable outcome influenced by the mean age (under 40 ) of the participants and overrepresentation $(41.7 \%)$ of patients on clozapine, a less TD-prone treatment. In an Indian cohort that matched patients for age, gender, and duration of therapy, an insignificant difference in risk was found between those on first-generation versus second-generation drugs, but this time risperidone was overrepresented in the latter class. ${ }^{9}$ Risperidone is a strong $\mathrm{D}_{2}$ antagonist of equipotent and even superior antipsychotic efficacy compared to haloperidol. ${ }^{10,11}$ Its use has been associated with a TD risk greater than other atypical agents, similar to typical (oral and depot) antipsychotic agents. ${ }^{12} \mathrm{~A}$ retrospective, populationbased cohort study that interrogated three different databases in Ontario on the incidence of TD in $>20,000$ senior citizens with dementia found no difference between those exposed to typical or atypical antipsychotics, but once again risperidone was overrerepresented. ${ }^{13}$ Reported figures continue to be influenced by the average age of the cohort under scrutiny, and one French study conducted in patients under age 40 found a prevalence rate of TD of $8.3 \% .{ }^{14}$ Any reduction in TD prevalence is worth mentioning, but recent findings are no reason to celebrate.

\section{Reappraisal of the Dopamine Receptor Supersensitivity HYPOTHESIS}

Several studies have attempted to shed light on the genetic risk and induction mechanisms for TD. Many different pharmacokinetic (linked to drug metabolism) and pharmacodynamic (linked to drug response) genetic markers of interest were examined by candidate gene investigations and genomewide association studies, with promising leads identified for CYP2D6, the dopamine receptor D2 and D3 genes, and the VMAT2 gene SLC18A2. ${ }^{15}$ Although a predictive multigene TD panel to determine the individual risk in a personalized medicine approach is not within reach, these studies indirectly support the dopamine hypothesis of TD.

The early concept of TD as a dopamine supersensitivity condition stemmed from observations that its intensity is aggravated or attenuated following the abrupt withdrawal or dosage increase of the offending drug, respectively, and enhanced following challenge with dopaminomimetics. In addition, an imbalance in striatal dopamine receptors was found following chronic antipsychotic drug exposure in experimental rats with upregulation in the density of striatal $\mathrm{D}_{2}$, not $\mathrm{D}_{1}$, receptors. ${ }^{16}$ This result was confirmed regardless of the presence or absence of TD-like vacuous chewing movements (VCM). ${ }^{17}$ The $\mathrm{D}_{2}$ receptor upregulation was confirmed in vitro in addition to increased oxidative stress indices, ${ }^{18}$ both prevented by lipoic acid, but this antioxidant failed to improve TD-like movements in a rat model. ${ }^{19}$ In another rat experiment, long-term exposure to haloperidol increased striatal $\mathrm{D}_{2}$ binding density, but no electrophysiological support for the development of supersensitive neuronal responses to selective $\mathrm{D}_{1}$ or $\mathrm{D}_{2}$ agonists was documented. ${ }^{20}$ Human positron emission tomography examining $\mathrm{D}_{2}$-like $\left(\mathrm{D}_{2 / 3}\right)$ receptor binding with the radioligand bromospiperone, ${ }^{21}$ or methylspiperone, ${ }^{22}$ did not find evidence for $\mathrm{D}_{2 / 3}$ receptor upregulation in subjects with TD examined off-drug. In another report, $\left[{ }^{11} \mathrm{C}\right]$ raclopride binding was found to be increased by $30-40 \%$ in nine subjects under long-term antipsychotic drug treatment with or without TD, but a positive correlation was observed between $\mathrm{D}_{2 / 3}$ binding level and TD intensity. ${ }^{23}$ Postmortem analysis of $\left[{ }^{3} \mathrm{H}\right]$ spiperone binding to $\mathrm{D}_{2}$ receptors in the putamen of subjects medicated for schizophrenia and controls ( $N=27 /$ group) showed no difference between those with or without $\mathrm{TD},{ }^{24}$ but such studies are inevitably conducted long after TD induction in senescent nigrostriatal pathways. 
Given the inconsistencies in published data, the dopamine receptor supersensitivity hypothesis was revisited in an experimental nonhuman primate model following long-term exposure to haloperidol or clozapine chosen as recognized prototypical drugs for conventional and atypical antipsychotics, respectively. ${ }^{25}$ According to the National Institute of Mental Health Psychoactive Drug Screening Program, these drugs display equivalent high in vitro affinity for dopamine $\mathrm{D}_{2}$ and $\mathrm{D}_{3}$ receptors. In rat tissue ex vivo, ${ }^{26}$ both haloperidol and clozapine display preferential $\mathrm{D}_{2}$ receptor occupancy, of greatest potency with haloperidol, but dose-dependent $\mathrm{D}_{3}$ receptor occupancy is always observed. At clinically relevant doses, $\mathrm{D}_{3}$ receptor occupancy is greater for clozapine (60\%) than for haloperidol (16\%). A nonhuman primate positron emission tomography imaging study using $\left[{ }^{11} \mathrm{C}\right]-(+)-$ PHNO confirmed $\mathrm{D}_{2}$ and $\mathrm{D}_{3}$ receptor occupancy with both drugs, with calculated $\mathrm{D}_{2}: \mathrm{D}_{3}$ selectivity values of 2.38 and 5.25 for haloperidol and clozapine, respectively. ${ }^{27}$ Unexpectedly, striatal $\mathrm{D}_{2}$-labeled [ $\left.{ }^{125} \mathrm{I}\right]$ iodosulpride binding level was found comparable between unmedicated and chronically medicated monkeys under long-term haloperidol exposure, regardless of TD status. ${ }^{28}$ Strong upregulation in $\left[{ }^{125}\right.$ I]iodosulpride binding was observed following haloperidol exposure in the internal globus pallidus, of equal magnitude between TD-expressing and TD-free animals. In contrast to the rat model, long-term haloperidol exposure caused a robust upregulation in $\mathrm{D}_{3}$-labeled $\left[{ }^{125} \mathrm{I}\right] 7-\mathrm{OH}-\mathrm{PIPAT}$ binding in all regions examined by standard receptor autoradiography, to a greater extent in the anterior striatal areas of TD-expressing monkeys. Using a double in situ hybridization procedure, a 3-fold increase in the fraction of preprotachykinin (PPT)-positive neurons co-expressing $\mathrm{D}_{3}$ mRNA was found in the anterior putamen, compared to PPT-negative cells, indicating that this upregulation mainly took place in direct striatal projection neurons. This increase correlated with TD intensity in the lateral putamen. Clozapine exposure spared $\mathrm{D}_{3}$ receptors in the basal ganglia. It is still unclear how striatal dopamine $\mathrm{D}_{3}$ receptor upregulation in direct striatal output neurons contributes to TD at the cellular or circuit level, but $\mathrm{D}_{3}$ receptors have been associated with behavioral sensitization and levodopa-induced dyskinesia along the direct pathway, ${ }^{29}$ possibly suggesting common mechanisms. The finding warrants confirmation in human studies. The foregoing results also raise the possibility of fundamental interspecies differences in terms of $\mathrm{D}_{3}$ receptor biology and suggest that caution should be used when interpreting experimental TD data generated in rodents.

The revival of the dopamine hypothesis of TD through striatal $D_{3}$, not $D_{2}$, receptor upregulation sets the stage for exploring different strategies designed to attenuate $D_{3}$ receptor availability or signaling. In view of their high affinity for dopamine (20-fold higher than $\mathrm{D}_{2}$ receptors), ${ }^{30}$ small changes in density or function may greatly impact on synaptic transmission. Further research will need to determine whether striatal monomeric or heteromeric $\mathrm{D}_{3}$ receptors are upregulated in a distinct way. In rats, half of the medium spiny neurons at origin of the direct striatal efferent pathway expressing dopamine $D_{1}$ receptor mRNA co-express $D_{3}$ receptor mRNA, ${ }^{31}$ and strong experimental evidence suggests the existence of $D_{1}-D_{3}$ receptor heterodimers in the striatum, where the $D_{3}$ partner may potentiate $D_{1}$ receptor-mediated responses spared by antipsychotic drugs and contribute to an overactive direct pathway. ${ }^{32}$ Thus, experimental drugs dampening neural activity along the direct pathway would be worth testing to improve motor behavior.
The experimental evidence generated in a relevant experimental TD model suggests key molecular mechanisms in the striatum to guide future development of preventive and palliative antidyskinetic strategies. At the signaling level, data suggest that cyclic adenosine monophosphate (cAMP)-independent mechanisms may compound the foregoing alterations in striatal $\mathrm{D}_{3}$ receptor membrane density and that the glycogen synthase kinase- 3 beta $(\mathrm{GSK}-3 \beta)$ is a key enzyme. In contrast to the rodent model, ${ }^{33}$ our primate results indirectly point to a posttranslational modification of striatal GSK- $3 \beta$ with a major shift in enzymatic activity toward its unphosphorylated (active) form in TD-expressing animals, with the potential to distinctly alter numerous targets, physiological processes, and neuroinflammation (Figure 1). ${ }^{34,35}$ This cascade of events in TD-expressing monkeys could contribute to overactive striatal dopamine signaling. Indeed, GSK-3 $\beta$ overactivity has been reported in a knockout mouse model lacking the dopamine transporter, producing a phenotype of motor hyperactivity and stereotypies. ${ }^{36}$ Of note, GSK-3 $\beta$ inhibition has been shown to decrease dopamine $D_{1}$ receptor activation and membrane density, ${ }^{37}$ with the potential to modulate direct pathway activity and mitigate hyperkinetic conditions. The GSK-3 $\beta$ inhibitors SB 216763, as well as two histamine $\mathrm{H}_{3}$ receptor agonists, provided benefit in a mouse model of motor hyperactivity or stereotypies resulting from dopamine $\mathrm{D}_{1}$ agonist exposure, ${ }^{38,39}$ and the antidyskinetic benefit afforded by TDZD8 (GSK-3 $\beta$ inhibitor) administration in a rat model of levodopa-induced dyskinesia was blocked by pretreatment with a selective dopamine $D_{1}$ agonist. ${ }^{40}$ Brain-penetrant, small molecules providing GSK-3 $\beta$ inhibition would certainly be worth testing in an experimental TD model.

Chemically diverse GSK-3 inhibitors, such as zinc, lithium, valproic acid, tetrahydrocannabinol, histamine $\mathrm{H} 3$ receptor agonists, cholinergic agents, glutamate N-methyl-D-aspartate (NMDA) antagonists, and others, have been tested in various animal models $\left(\right.$ see review ${ }^{41}$ ). For instance, both lithium and valproate increased (inactive) phospho[Ser9]GSK-3 $\beta$ levels in the rat frontal cortex. ${ }^{42}$ Chronic lithium use has been reported to protect and attenuate TD in a population of schizophrenic patients, ${ }^{43}$ whereas short-term effects were disappointing. ${ }^{44}$ Valproic acid improved the VCM response in the reserpine rat model, ${ }^{45}$ but no clinical benefit was documented. ${ }^{46}$ On the other hand, the antioxidant ginkgo biloba extract EGb761 has been shown to inhibit (Ser9) phosphorylation of GSK-3 $\beta^{47}$ but somehow reduced TD in a single placebo-controlled clinical trial. ${ }^{48}$

Important knowledge gaps need to be filled in order to improve TD management. Several non-dopaminergic smallmolecule candidates could eventually find their way to the clinic in order to prevent or alleviate TD. The most promising targets appear those able to dampen neural activity along the direct striatal output pathway. The ideal approach would be to design a novel class of antipsychotic drugs avoiding the detrimental neurochemical events underlying TD.

\section{Clinical Efficacy of New VMat2 Inhibitors}

Blockade of VMAT2 function has been used as a strategy to deplete monoamine stores and manage different hyperkinetic conditions including troublesome TD. For decades, tetrabenazine and reserpine were the only drugs available in that class, with preference to the former because of its selectivity for VMAT2 over VMAT1 binding, reversibility, and shorter duration of 


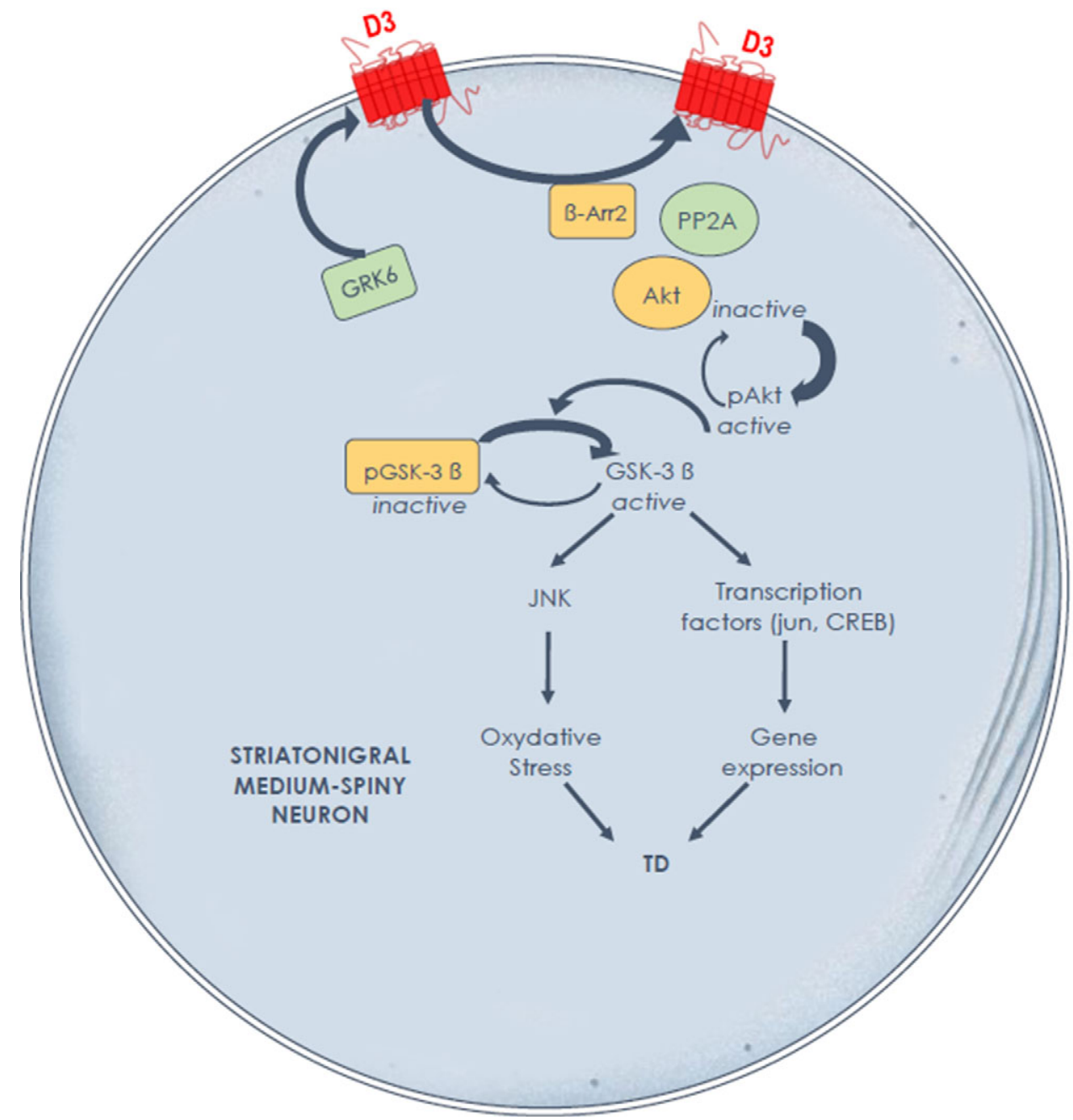

Figure 1: Hypothesis of overactive dopamine signaling Along the direct striatal output pathway in

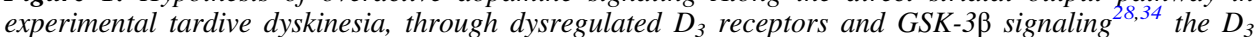
receptor not only displays high affinity for dopamine, but also has the potential to amplify $D_{1}$ receptor-

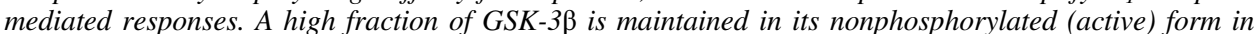
nonhuman primates with tardive dyskinesia. Further studies are needed to determine the causal link between these signaling alterations and tardive dyskinesia induction and maintenance.

response, decreasing adverse effects. The pharmacokinetic and pharmacodynamic profiles of tetrabenazine have complicated its use. ${ }^{49}$ It is a mixture of enantiomers undergoing liver metabolism by the cytochrome P450 enzymes CYP2D6 with some contribution by CYP1A2. The metabolites of the $\beta$-isomers display lowaffinity antagonism for dopamine $\mathrm{D}_{2}$ receptors, which may become problematic if the drug accumulates. Metabolites have short half-lives between 2 and 8 hours, resulting in plasma drug fluctuations attended by repeated dosing during the day. A careful slow titration is required, up to an approximate daily dose of $100 \mathrm{mg}$ if necessary. The Food and Drug Administration (FDA) has recommended proceeding to CYP2D6 genotyping in individuals taking over $50 \mathrm{mg}$ daily, but the advantages of genotyping analysis in clinical practice remain uncertain. Expectedly, poor metabolizers tend to display more adverse effects than others. ${ }^{50}$ The efficacy of tetrabenazine has been tested in various hyperkinetic movement disorders, mainly in small open-label studies. ${ }^{51}$ Sustained improvement in TD ratings was observed in over $80 \%$ of a group of 149 patients according to a retrospective study that allowed a daily dose up to $300 \mathrm{mg} .{ }^{52}$ Dose-dependent adverse effects such as somnolence $(27 \%)$, depression (15\%), parkinsonism $(12 \%)$, and akathisia (9\%) were documented. ${ }^{53}$ Depression occurred more commonly in those with a pre-existing history (50/78 cases). Other uncommon potentially serious adverse effects include neuroleptic malignant syndrome, dysphagia, pneumonia, corrected QT interval prolongation, and suicide attempts. Coadministration of strong cytochrome P450 2D6 inhibitors (e.g., fluoxetine, paroxetine, bupropion, quinidine, and terbinafine) is liable to raise the risk of adverse events and warrants caution.

It is against these limitations and lack of FDA-approved drug treatment in TD that two novel VMAT2 inhibitors, valbenazine and deutetrabenazine, were approved in the USA as add-on therapy following rigorous protocols involving central video rating. Valbenazine is a highly selective reversible VMAT2 inhibitor converted by hydrolysis of the valine ester to $(+)$ - $\alpha$-dihydrotetrabenazine, one of the main metabolites of 
tetrabenazine. Its half-life of $20 \mathrm{hrs}$ allows single daily dosing. It is slowly metabolized by CYP3A4/5, with some contribution by CYP2D6, offering narrowed off-target receptor binding and sideeffects profiles. In 2013, a phase 2, randomized, placebocontrolled, 6-week flexible dose study (NBI-98854-1202 trial or KINECT Phase 2 study, $\mathrm{N}=102$ ) was completed in subjects with moderate to severe TD that allowed a daily dose range of valbenazine between 25 and $75 \mathrm{mg} .{ }^{54}$ Ten participants (5 in each arm) discontinued the trial. After titration, $76 \%$ of patients in the active drug arm reached the maximal dose. The active drug improved baseline TD ratings, and $49 \%$ of participants showed $\geq 50 \%$ improvement in TD rating compared to $18 \%$ for the placebo group. The 6-week improvement on the rating scale was corroborated by the Clinical Global Impression of Change-TD (CGI-TD) score. No serious adverse events occurred, and fatigue and headache $(10 \%)$ were the most common side effects compared to placebo (4\%). In the 6-week KINECT Phase 3 study $(N=234),{ }^{55}$ fixed doses of $40 \mathrm{mg}$ and $80 \mathrm{mg}$ improved blinded TD ratings and CGI-TD score in a sustained manner, and the proportion of participants showing $\geq 50 \%$ improvement in TD rating was $40 \%(80 \mathrm{mg}$ ) and $24 \%$ (40 mg) compared to $9 \%$ for placebo. These figures were confirmed in the blinded 1-year extension KINECT Phase 3 study $(N=198$, all on active drug), completed by $61 \%$ of the enrolled participants. ${ }^{56}$ The discontinuation rate due to adverse effects was $15.7 \%$. The most common adverse effects included headache $(7.1 \%)$, urinary tract infection (6.6\%), diarrhea and dizziness (5.6\%), suicidal ideation (5.1\%), and depression (4\%). The drug did not induce or worsen akathisia or parkinsonism. Three participants experienced syncope, but no clinically relevant electrocardiogram (ECG) alterations were documented. Thus, ECG monitoring is advised only for those known for corrected QT prolongation or arrhythmias. Long-term safety for up to 48 weeks was also assessed in the open-label KINECT Phase 4 study ( $N=167$ at entry). ${ }^{57}$ Of note, $27 \%$ of participants were taking an anticholinergic agent, perhaps influencing the detection of parkinsonism. In the first 4 weeks, $22 \%$ of participants experienced at least one treatment-emergent adverse event, considered mild to moderate in $97.5 \%$ of cases, similar to those previously reported. After week 4, serious treatment-emergent adverse events, or treatment-emergent adverse events leading to discontinuation, were recorded in $13.7 \%$ and $11.8 \%$ of participants, respectively. Dose reduction to $40 \mathrm{mg} / \mathrm{d}$ was required in $11(6.7 \%)$ participants. Dose reduction should be considered for those on potent CYP2D6 or CYP3A4 inhibitors, and coadministration with a potent CYP3A4 inducer (e.g., rifampin, phenytoin, carbamazepine, St. John's wort) is not recommended.

For the synthesis of deutetrabenazine, nontoxic atoms of deuterium replaced hydrogen in the molecule and strengthened bonds with carbon, thus stabilizing its metabolism and smoothing fluctuations. This allows twice-daily dosing within a daily dose range of $12-48 \mathrm{mg}$ much lower than for tetrabenazine, thereby reducing the adverse effects profile and potential for dopamine $\mathrm{D}_{2}$ receptor occupancy. In two 12-week placebo-controlled studies (Aim to Reduce Movements in Tardive Dyskinesia [ARM-TD], Addressing Involuntary Movements in Tardive Dyskinesia [AIM-TD] $)^{58,59}$ and their open-label extension study of up to 2 years, ${ }^{60}$ active treatment was well tolerated and produced rapid and sustained reduction in mean TD rating along the Abnormal Involuntary Movements Scale. In the AIM-TD study $(N=298)$ that included three fixed active treatment arms of 12, 24, and $36 \mathrm{mg}$, significance in TD rating improvement was achieved for the 24- and 36-mg arms. ${ }^{59}$ The proportion of patients showing $\geq 50 \%$ improvement in TD rating was greater for the $36-\mathrm{mg}$ (33\%) and 24-mg (35\%) arms than in the placebo arm (12\%). The incidence of adverse effects was similar to placebo, including suicidality $(2.7 \%)$. During an extended open-label study ( $N$ $=343),{ }^{60} 76 \%$ of participants received at least 54 weeks of treatment and $35 \%$ of participants reached the highest daily dose of $48 \mathrm{mg}$ by week 80 . Adverse effects were deemed mild to moderate in most cases, including somnolence and anxiety $(8.5 \%)$, and depression $(7.9 \%)$.

Post-marketing clinical use of the different VMAT2 inhibitors for various hyperkinetic indications and treatment durations has generally been favorable, with preference for the newer agents in view of their better tolerability. ${ }^{61}$ Nonetheless, cases of valbenazine-induced parkinsonism have been reported in subjects over age $40,{ }^{62}$ raising the importance to carefully monitor patients particularly during the first months of treatment. The demonstrated tolerability and safety profile of the new VMAT2 inhibitors will hopefully promote their approval by other national regulatory agencies. These efficacy data extend the practical experience gathered from the clinical use of tetrabenazine and fuel the dopamine hypothesis of TD.

\section{Management Algorithm}

In view of the existing evidence, preventive measures clearly remain a key aspect of TD management, particularly in older age groups. Antipsychotic drugs should only be prescribed for approved indications and carefully monitored by routine screening for abnormal movement disorders. Modifiable risk factors should be identified in order to minimize the incidence and intensity of TD. These include diabetes, smoking, substance abuse including alcohol and cocaine, and anticholinergic co-treatment. ${ }^{63}$ This step should be part of any management algorithm for TD and given due consideration before initiating antidyskinetic medications. Neurologists are typically asked to assess those with troublesome motor symptomatology and those displaying unusual TD variants such as tardive dystonia, tardive akathisia, tardive chorea, or tardive tics, suggest evidence-based therapeutic interventions, and monitor progress. The phenomenology and diagnosis must be ascertained in order to guide therapy (Figure 2). Other hyperkinetic movement disorders need to be ruled out, including acute, reversible drug-induced conditions, edentulous or denture orodyskinesia, psychiatric behaviors such as compulsions, agitation, or mannerisms, autoimmune and paraneoplastic disorders, neurosyphilis, Fahr syndrome, and hereditary diseases (Huntington's disease, neuroacanthocytosis, McLeod syndrome, spinocerebellar ataxia-17, and neurodegeneration with brain iron accumulation). In cases with predominant oromandibular dystonia, primary dystonia, neuroacanthocytosis, Lesch-Nyhan syndrome, neurodegeneration with brain iron accumulation, Wilson's disease, spinocerebellar ataxia-8, cerebrotendinous xanthomatosis, and GM1 or GM2 gangliosidosis are among the rare conditions that may need some consideration.

A Cochrane group conducted a systematic review of over 100 randomized trials on $\mathrm{TD}$, concluding to the inability to construct an algorithm of treatment to manage TD ${ }^{65}$ Typical management decisions were addressed, including a dose reduction or switch of 


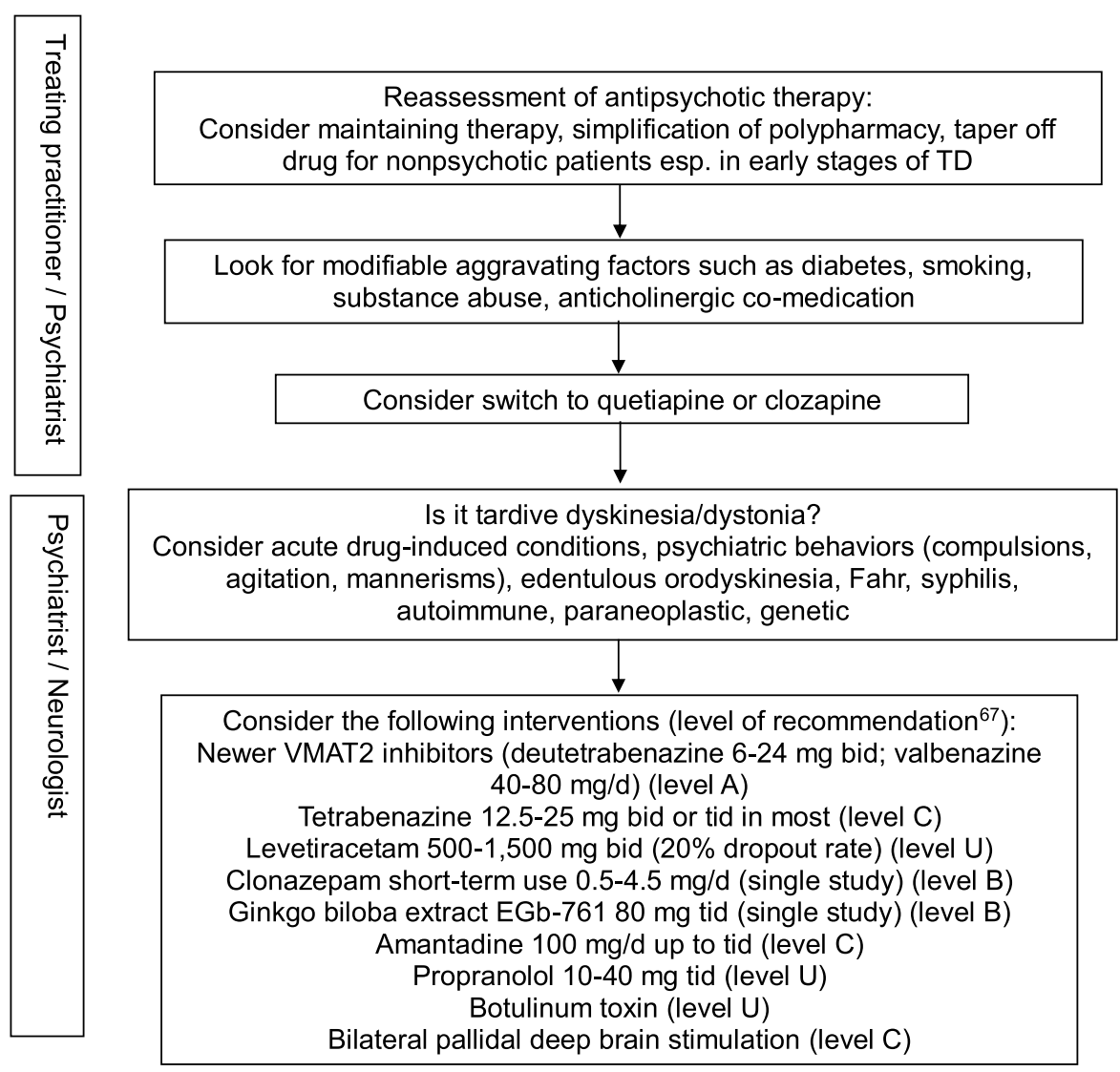

Figure 2: Practical management algorithm for troublesome tardive dyskinesia (inspired from Caroff et al. ${ }^{64}$ ).

the offending antipsychotic drug used, and use of adjunct therapies. According to the authors, the low quality of available evidence justified this outcome. Another authoritative review of all therapeutic interventions for TD published until 2011 was conducted by a subcommittee of the American Academy of Neurology. ${ }^{66}$ The panel classified each selected study and graded evidence-based recommendations focused around five basic management issues: 1 . Is withdrawal of dopamine receptor blocking agents an effective tardive syndromes treatment? 2. Does switching from typical to atypical dopamine receptor blocking agents reduce tardive syndromes symptoms? 3. What is the efficacy of pharmacologic agents in treating tardive syndromes? 4. Do patients with tardive syndromes benefit from chemodenervation with botulinum toxin? 5. Do patients with tardive syndromes benefit from surgical therapy? Given the paucity of well-designed, double-blind, randomized controlled trials, not a single intervention reached Level A recommendation. Insufficient evidence (Level U) or conflicting data made impossible to support or refute the use of many different putative antidyskinetic interventions, including botulinum toxin. The panel concluded that clonazepam and ginkgo biloba extracts (Level B) should be considered as treatment and that amantadine and tetrabenazine (Level C) might be considered as alternatives. Masking TD symptoms with risperidone or olanzapine found some support in the literature, but the safety of this strategy beyond one year has not been adequately addressed, and caution was advised when using these agents. An update of this systematic review identified a total of 687 publications relevant to the treatment of tardive syndromes between 2012 and 2017, of which 15 new articles were analyzed. ${ }^{67}$ This time, the new VMAT2 inhibitors deutetrabenazine and valbenazine reached Level A recommendation as effective therapy, whereas the initial recommendations were maintained for the other pharmacological interventions and chemodenervation with botulinum toxin. The experts proposed an algorithm for management of troublesome TD involving initial readjustment of psychotropic medications, then consideration of suppressive agents first with newer VMAT2 inhibitors (Level A), then clonazepam and ginkgo biloba extracts (Level B), or eventually amantadine (Level C). Other GAB Aergic drugs tested in open-label trials or case series, such as kamishoyosan, ${ }^{68}$ zolpidem, ${ }^{69}$ and sodium oxybate, ${ }^{70}$ await controlled studies before consideration. Among non-pharmacological interventions, bilateral pallidal deep brain stimulation reached Level C recommendation status, mainly based on a single class II study of 19 patients with severe TD or tardive dystonia. ${ }^{71}$ The participants were evaluated blindly with and without neurostimulation 6 months postoperatively, and 14 of them were rated along standard scales for periods of time extending between 6 and 11 years postoperatively. Sustained benefit in oral and extra-oral TD movements was observed with a reduction in TD scores $>50 \%$ compared to preoperative values. Unfortunately, a recent multicentre, randomized, sham-controlled, but underpowered German study on tardive dystonia failed to reproduce those results, as the primary endpoint, which consisted of the percent 
change in blinded, video-based, Burke-Fahn-Marsden Dystonia Rating Scale (BFMDRS) severity score at 3 months following the start of neurostimulation compared to sham stimulation, was not met. $^{72}$ Nonetheless, mean improvement in severity score at 3 months compared to preoperative values was significantly greater in the neurostimulation group (22.8\%) than in the sham group $(12.0 \%)$, and other secondary outcome measures favored neurostimulation. A single-center study involving a young set of 10 consecutive patients (all but one under age 40) with tardive dystonia who underwent bilateral subthalamic nucleus (STN) electrode placement reported remarkable benefit in nine participants, with a mean improvement of $87.3 \%$ in BFMDRS severity score at 6 months compared to preoperative values, sustained over an extended follow-up period. ${ }^{73}$ Of note, benefit was observed on postoperative day 1 in five patients, suggesting a microlesion effect. It remains unclear whether the STN is a better target for a subset of TD patients with predominant dystonia.

Other comprehensive reviews have been completed in order to document the best practice and feed an evidence-based algorithm. A Canadian group of experts recently conducted their own systematic review of 346 TD treatment articles available until June 2017, including 10 Cochrane reviews and publications targeting issues such as antipsychotic dose reduction, cessation, or switching to an atypical drug, or upward dose titration to mask troublesome TD manifestations. ${ }^{74}$ In their Level B treatment recommendations, they considered antipsychotic drug cessation or upward titration not viable options in subjects with chronic schizophrenia, but careful drug withdrawal should be considered in other groups particularly in early stages of TD. They found insufficient evidence to recommend dose reduction, a strategy viewed as a legitimate way to prevent TD during maintenance antipsychotic drug therapy. Switching to a low-affinity dopamine D2 receptor blocker, such as clozapine and quetiapine, may be effective to reduce TD, but improvement may be delayed. The group also analyzed the evidence linking anticholinergic co-medications with TD and found very little support to support the withdrawal of these agents, which may in turn worsen parkinsonism. Keeping in mind the inconsistent outcome of this option and threat of worsened parkinsonism, they concluded that discontinuation of anticholinergic medications may be worth some consideration for the treatment of TD (Level C).

Other investigators collected the literature on drug treatment of TD published between 2007 and 2016 and identified 261 publications, of which 26 articles were reviewed including five meta-analyses. ${ }^{64}$ The main findings were used to generate a stepwise management algorithm of troublesome TD implicating the treating psychiatrist and consultant neurologist, including initial assessment of the diagnosis and severity of TD, a review of the current antipsychotic drug treatment, including individual decision to discontinue, reduce, or switch antipsychotic, review of anticholinergic co-medication, and trials of antidyskinetic drugs with preference for the newly approved selective VMAT2 inhibitors. They then used the Delphi method, a systematic group communication process, to survey 29 North American experts ( 23 from the field of psychiatry, 6 from the field of neurology) in two rounds, who were asked to examine a selection of 18 recent publications reflecting the best evidence-based TD practice and research, and answer a maximum of 23 questions. ${ }^{75}$ The degree of respondent agreement was assessed for targeted issues including TD screening methods, diagnosis, and treatment.
Circumstances calling for a neurologist opinion were delineated. Unanimous consensus was reached on the need to periodically screen all patients under chronic antipsychotic drugs for $\mathrm{TD}$, and on considering modifications to the antipsychotic drug regimen for patients with troublesome TD who cannot be safely withdrawn from antipsychotic therapy, with a high level of agreement for switching to an atypical second-generation drug or clozapine. A majority agreement was found for modifications of the anticholinergic co-medication, including options such as discontinuation, dose reduction, or switching to amantadine. Using different selective VMAT2 inhibitors was unanimously considered the first-line pharmacological option when an antidyskinetic strategy is necessary, and improvement of at least $30 \%$ relative to the baseline Abnormal Involuntary Movements Scale total score was considered clinically significant, representing in another study a two-point decrease in score for a minimal clinically important difference attributed to an intervention. ${ }^{76}$

Progress has been made in the last 5 years in the field of TD. The impact of the condition in everyday life and its current epidemiology are better understood. Experimental research has begun to unveil potentially important mechanisms suggestive of overactive striatal dopamine signaling along the direct striatonigral pathway in TD. New effective VMAT2 inhibitors have been approved following refined protocols that constitute stepping stones to generate sound data in the future. These drugs were approved by the US FDA and were added to a treatment algorithm emerging from the best experimental evidence and practice. These advances, together with cautious antipsychotic drug prescription, and development of a new generation of drugs ${ }^{77}$ hopefully able to avoid or reverse some of the signaling alterations linked to TD, give hope to improved prevention and management of TD.

\section{ACKNOWLEDGMenTS}

The preclinical TD program was supported by the Canadian Institutes of Health Research, grant MOP-81321, and grant MOP130407 to Prof. Daniel Lévesque, University of Montreal. The author sincerely thanks Mrs. Marie-Luce Houde-Simard for her contribution to the graphic presentation, and Dr. Stanley N. Caroff, MD, Perelman School of Medicine, University of Pennsylvania, Philadelphia (PA, USA), who provided expert editorial comments.

\section{CONFLict OF INTEREST}

The author was involved in the KINECT 3 studies sponsored by Neurocrine Biosciences, Inc., San Diego, CA, USA.

\section{REFERENCES}

1. Friedman JH. Tardive syndromes. Continuum (Minneap Minn) 2019;25(4, Movement Disorders):1081-98.

2. McEvoy J, Gandhi SK, Rizio AA, et al. Effect of tardive dyskinesia on quality of life in patients with bipolar disorder, major depressive disorder, and schizophrenia. Quality Life Res. 2019;28:3303-12.

3. Emsley R, Niehaus DJ, Oosthuizen PP, Koen L, Chiliza B, Fincham D. Subjective awareness of tardive dyskinesia and insight in schizophrenia. Eur Psych. 2011;26:293-6.

4. Caroff SN, Yeomans K, Lenderking WR, et al. RE-KINECT: a prospective study of the presence and healthcare burden of tardive 
dyskinesia in clinical practice settings. J Clin Psychopharmacol. 2020;40:259-68.

5. Strassnig M, Rosenfeld A, Harvey PD. Tardive dyskinesia: motor system impairments, cognition and everyday functioning. CNS Spectrums 2018;23:370-7.

6. Blanchet PJ, Popovici R, Guitard F, Rompré P, Lamarche C, Lavigne GJ. Pain and denture condition in edentulous orodyskinesia: comparisons with tardive dyskinesia and control subjects. Mov Disord. 2008;23:1837-42.

7. Woods SW, Morgenstern H, Saksa JR, et al. Incidence of tardive dyskinesia with atypical versus conventional antipsychotic medications: a prospective cohort study. J Clin Psych. 2010;71:463-74.

8. Carbon M, Hsieh CH, Kane JM, Correll CU. Tardive dyskinesia prevalence in the period of second-generation antipsychotic use: a meta-analysis. J Clin Psych. 2017;78(3):e264-78.

9. Achalia RM, Chaturvedi SK, Desai G, Rao GN, Prakash O. Prevalence and risk factors associated with tardive dyskinesia among Indian patients with schizophrenia. Asian J Psych. 2014;9:31-5.

10. Tarsy D, Baldessarini RJ, Tarazi FI. Effects of newer antipsychotics on extrapyramidal function. CNS Drugs 2002;16(1):23-45.

11. Csernansky JG, Mahmoud R, Brenner R, for the Risperidone-USA79 Study Group. A comparison of risperidone and haloperidol for the prevention of relapse in patients with schizophrenia. New Eng J Med 2002;346:16-22.

12. Novick D, Haro JM, Bertsch J, Haddad PM. Incidence of extrapyramidal symptoms and tardive dyskinesia in schizophrenia. Thirty-six-month results from the European Schizophrenia Outpatient Health Outcomes Study. J Clin Psychopharmacol. 2010;30:531-40.

13. Lee PE, Sykora K, Gill SS, et al. Antipsychotic medications and drug-induced movement disorders other than parkinsonism: a population-based cohort study in older adults. J Am Geriatr Soc. 2005;53:1374-9.

14. Misdrahi D, Tessier A, Daubigney A, et al. Prevalence of and risk factors for extrapyramidal side effects of antipsychotics: results from the national FACE-SZ cohort. J Clin Psych. 2019;80(1):18m12246.

15. Zai CC, Maes MS, Tiwari AK, Zai GC, Remington G, Kennedy JL. Genetics of tardive dyskinesia: promising leads and ways forward. J Neurol Sci. 2018;389:28-34.

16. See RE, Aravagiri M, Ellison GD. Chronic neuroleptic treatment in rats produces persisting changes in GABAA and dopamine D-2, but not dopamine D-1 receptors. Life Sci. 1989;44:229-36.

17. Knable MB, Hyde TM, Herman MM, et al. Quantitative autoradiography of dopamine-D1 receptors, D2 receptors, and dopamine uptake sites in postmortem striatal specimens from schizophrenic patients. Biol Psych. 1994;36:827-35.

18. Deslauriers J, Lefrancois M, Larouche A, Sarret P, Grignon S. Antipsychotic-induced DRD2 upregulation and its prevention by alpha-lipoic acid in SH-SY5Y neuroblastoma cells. Synapse 2011;65:321-31.

19. Lister J, Andreazza AC, Navaid B, et al. Lipoic acid and haloperidolinduced vacuous chewing movements: implications for prophylactic antioxidant use in tardive dyskinesia. Prog NeuroPsychopharmacol Biol Psychiat. 2017;72:23-9.

20. Jiang LH, Kasser RJ, Altar CA, Wang RY. One year of continuous treatment with haloperidol or clozapine fails to induce a hypersensitive response of caudate putamen neurons to dopamine D1 and D2 receptor agonists. J Pharmacol Exp Ther. 1990;253:1198-205.

21. Blin J, Baron JC, Cambon H, et al. Striatal dopamine D2 receptors in tardive dyskinesia: PET study. J Neurol Neurosurg Psych. 1989;52:1248-52.

22. Andersson U, Eckernäs SA, Hartvig P, et al. Striatal binding of 11CNMSP studied with positron emission tomography in patients with persistent tardive dyskinesia: no evidence for altered dopamine D2 receptor binding. J Neural Transm [GenSect] 1990; 79:215-26.

23. Silvestri S, Seeman MV, Negrete JC, et al. Increased dopamine D2 receptor binding after long-term treatment with antipsychotics in humans: a clinical PET study. Psychopharmacology (Berl). 2000;152:174-80
24. Kornhuber J, Riederer P, Reynolds GP, et al. 3H-Spiperone binding sites in post-mortem brains from schizophrenic patients: relationship to neuroleptic drug treatment, abnormal movements, and positive symptoms. J Neural Transm. 1989;75:1-10.

25. Blanchet PJ, Parent MT, Rompré PH, Lévesque D. Relevance of animal models to human tardive dyskinesia. Behav Brain Funct. 2012;8:12.

26. Davoodi N, te Riele P, Langlois X. Examining dopamine D3 receptor occupancy by antipsychotic drugs via [3H]7-OH-DPAT ex vivo autoradiography and its cross-validation via c-fos immunohistochemistry in the rat brain. Eur $\mathrm{J}$ Pharmacol. 2014;740:669-75.

27. Girgis RR, Xu X, Miyake N, et al. In vivo binding of antipsychotics to D3 and D2 receptors: a PET study in baboons with [11C]-(+)PHNO. Neuropsychopharmacology 2011;36:887-895.

28. Mahmoudi S, Lévesque D, Blanchet PJ. Upregulation of dopamine D3, not D2, receptors correlates with tardive dyskinesia in a primate model. Mov Disord. 2014;29:1125-33.

29. Bézard E, Ferry S, Mach U, et al. Attenuation of levodopa-induced dyskinesia by normalizing dopamine D3 receptor function. Nat Med. 2003;9:762-7.

30. Sokoloff P, Giros B, Martres MP, Bouthenet ML, Schwartz JC. Molecular cloning and characterization of a novel dopamine receptor (D3) as a target for neuroleptics. Nature 1990;347:146-51.

31. Surmeier DJ, Song WJ, Yan Z. Coordinated expression of dopamine receptors in neostriatal medium spiny neurons. J Neurosci. 1996;16:6579-91.

32. Marcellino D, Ferré S, Casadó V, et al. Identification of dopamine D1-D3 receptor heteromers. Indications for a role of synergistic D1-D3 receptor interactions in the striatum. J Biol Chem. 2008;283:26016-25.

33. Emamian ES, Hall D, Birnbaum MJ, et al. Convergent evidence for impaired AKT1-GSK3beta signaling in schizophrenia. Nat Genet. 2004;36:131-7.

34. Hernandez G, Mahmoudi S, Cyr M, Diaz J, Blanchet PJ, Lévesque D. Tardive dyskinesia is associated with altered putamen Akt/ GSK-3 $\beta$ signaling in nonhuman primates. Mov Disord. 2019;34:717-26.

35. Golpich M, Amini E, Hemmati F, et al. Glycogen synthase kinase-3 beta (GSK-3 $\beta$ ) signaling: implications for Parkinson's disease. Pharmacol Res. 2015;97:16-26.

36. Beaulieu JM, Sotnikova TD, Yao WD, et al. Lithium antagonizes dopamine-dependent behaviors mediated by an AKT/glycogen synthase kinase 3 signaling cascade. Proc Natl Acad Sci. 2004;101:5099-104.

37. Wang JR, Sun PH, Ren ZX, Meltzer HY, Zhen XC. GSK-3 $\beta$ interacts with dopamine D1 receptor to regulate receptor function: implication for prefrontal cortical D1 receptor dysfunction in schizophrenia. CNS Neurosci Ther. 2017;23:174-87.

38. Miller JS, Tallarida RJ, Unterwald EM. Inhibition of GSK3 attenuates dopamine D1 receptor agonist-induced hyperactivity in mice. Brain Res Bull. 2010;82:184-87.

39. Rapanelli M, Frick LR, Horn KD, et al. The histamine $\mathrm{H} 3$ receptor differentially modulates mitogen-activated protein kinase (MAPK) and Akt signaling in striatonigral and striatopallidal neurons. J Biol Chem. 2016;291:21042-52.

40. Xie CI, Lin JY, Wang MH, et al. Inhibition of glycogen synthase kinase- $3 \beta$ (GSK-3 $\beta$ ) as potent therapeutic strategy to ameliorates L-dopa-induced dyskinesia in 6-OHDA parkinsonian rats. Sci Rep. 2016 Mar 21;6:23527; doi: 10.1038/srep23527

41. Chico LK, Van Eldik LJ, Watterson DM. Targeting protein kinases in central nervous system disorders. Nat Rev Drug Discov. 2009;8:892-909.

42. Kozlovsky N, Amar S, Belmaker RH, Agam G. Psychotropic drugs affect Ser9-phosphorylated GSK-3 $\beta$ protein levels in rodent frontal cortex. Int J Neuropsychopharmacol. 2006;9:337-42.

43. van Harten PN, Hoek HW, Matroos GE, van Os J. Evidence that lithium protects against tardive dyskinesia: the Curaçao Extrapyramidal syndromes study VI. Eur Neuropsychopharmacol. 2008;18:152-5.

44. MacKay AV, Sheppard GP, Saha BK, et al. Failure of lithium treatment in established tardive dyskinesia. Psychol Med. 1980;10:583-7. 
45. Peixoto MF, Abílio VC, Silva RH, Frussa-Filho R. Effects of valproic acid on an animal model of tardive dyskinesia. Behav Brain Res. 2003;142:229-33.

46. Fisk GG, York SM. The effect of sodium valproate on tardive dyskinesia-revisited. Br J Psych. 1987;150:542-6.

47. Kwon KJ, Lee EJ, Cho KS, et al. Ginkgo biloba extract (Egb761) attenuates zinc-induced tau phosphorylation at Ser262 by regulating GSK $3 \beta$ activity in rat primary cortical neurons. Food Funct. 2015;6:2058-67.

48. Zhang WF, Tan YL, Zhang XY, et al. Extract of Ginkgo biloba treatment for tardive dyskinesia in schizophrenia: a randomized, double-blind, placebo-controlled trial. J Clin Psych. 2011;72:615-21.

49. Guay DRP. Tetrabenazine, a monoamine-depleting drug used in the treatment of hyperkinetic movement disorders. Am J Geriatr Pharmacother. 2010;8:331-73.

50. Mehanna R, Hunter C, Davidson A, Jimenez-Shahed J, Jankovic J. Analysis of CYP2D6 genotype and response to tetrabenazine. Mov Disord. 2013;28:210-5.

51. Leung JG, Breden EL. Tetrabenazine for the treatment of tardive dyskinesia. Ann Pharmacother. 2011;45:525-31.

52. Kenney C, Hunter C, Jankovic J. Long-term tolerability of tetrabenazine in the treatment of hyperkinetic movement disorders, Mov. Disord. 2007;22:193-7.

53. Kenney C, Hunter C, Mejia N, Jankovic J. Is history of depression a contraindication to treatment with tetrabenazine? Clin Neuropharmacol. 2006;29:259-64.

54. O'Brien CF, Jimenez R, Hauser RA, Factor SA, Burke J, Mandri D, Castro-Gayol JC. NBI-98854, a selective monoamine transport inhibitor for the treatment of tardive dyskinesia: a randomized, double-blind, placebo-controlled study. Mov Disord. 2015; 30:1681-7.

55. Hauser RA, Factor SA, Marder SR, et al. KINECT 3: a phase 3 randomized, double-blind, placebo-controlled trial of valbenazine for tardive dyskinesia. Am J Psych. 2017;174:476-84.

56. Factor SA, Remington G, Comella CL, et al. The effects of valbenazine in participants with tardive dyskinesia: results of the 1-year KINECT 3 extension study. J Clin Psych. 2017;78:1344-50.

57. Marder SR, Singer C, Lindenmayer JP, et al. A phase 3, 1-year, open-label trial of valbenazine in adults with tardive dyskinesia. J Clin Psychopharmacol. 2019;39:620-7.

58. Fernandez HH, Factor SA, Hauser RA, et al. Randomized controlled trial of deutetrabenazine for tardive dyskinesia: the ARM-TD study. Neurology 2017;88:2003-10.

59. Anderson KE, Stamler D, Davis MD, et al. Deutetrabenazine for treatment of involuntary movements in patients with tardive dyskinesia (AIM-TD): a double-blind, randomised, placebocontrolled, phase 3 trial. Lancet Psych. 2017;4:595-604.

60. Fernandez HH, Stamler D, Davis MD, et al. Long-term safety and efficacy of deutetrabenazine for the treatment of tardive dyskinesia. J Neurol Neurosurg Psych. 2019;90:1317-23.

61. Niemann N, Jankovic J. Real-world experience with VMAT2 inhibitors. Clin Neuropharm. 2019;42:37-41.
62. Akbar U, Kim DS, Friedman JH. Valbenazine-induced parkinsonism. Parkinsonism Rel Disord. 2020;70:13-4.

63. Solmi M, Pigato G, Kane JM, Correll CU. Clinical risk factors for the development of tardive dyskinesia. J Neurol Sci. 2018;389:21-7.

64. Caroff SN, Campbell EC, Carroll B. Pharmacological treatment of tardive dyskinesia: recent developments. Exp Rev Neurother. 2017;17:871-81. doi: 10.1080/14737175.2017.1358616

65. Bergman H, Walker DM, Nikolakopoulou A, Soares-Weiser K, Adams CE. Systematic review of interventions for treating or preventing antipsychotic-induced tardive dyskinesia. Health Technol Assess. 2017;21(43).

66. Bhidayasiri R, Fahn S, Weiner WJ, Gronseth GS, Sullivan KL, Zesiewicz TA. Evidence-based guideline: treatment of tardive syndromes. Report of the Guideline Development Subcommittee of the American Academy of Neurology. Neurology 2013;81:463-9.

67. Bhidayasiri R, Jitkritsadakul O, Friedman JH, Fahn S. Updating the recommendations for treatment of tardive syndromes: a systematic review of new evidence and practical treatment algorithm. J Neurol Sci. 2018;389:67-75.

68. Lee JG, Shin BS, Lee YC, et al. Clinical effectiveness of the Kampo medicine kamishoyosan for adjunctive treatment of tardive dyskinesia in patients with schizophrenia: a 16-week open trial. Psych Clin Neurosci. 2007;61(5):509-14.

69. Waln O, Jankovic J. Zolpidem improves tardive dyskinesia and akathisia. Mov Disord. 2013;28:1748-9.

70. D'Arrigo AM, Campiglio L, Casellato C, et al. Tardive myoclonic dyskinesia responsive to sodium oxybate. Clin Neuropharm 2018;41:194-6.

71. Pouclet-Courtemanche H, Rouaud T, Thobois S, et al. Long-term efficacy and tolerability of bilateral pallidal stimulation to treat tardive dyskinesia. Neurology 2016;86:651-9.

72. Gruber D, Südmeyer M, Deuschl G, et al., for the DBS study group for dystonia. Neurostimulation in tardive dystonia/dyskinesia: a delayed start, sham stimulation-controlled randomized trial. Brain Stim. 2018;11:1368-77.

73. Deng ZD, Li DY, Zhang CC, et al. Long-term follow-up of bilateral subthalamic deep brain stimulation for refractory tardive dystonia. Parkinsonism Rel Disord. 2017;41:58-65.

74. Ricciardi L, Pringsheim T, Barnes TRE, et al. Treatment recommendations for tardive dyskinesia. Can J Psych. 2019;64: 388-99.

75. Caroff SN, Citrome L, Meyer J, et al. A modified Delphi consensus study of the screening, diagnosis, and treatment of tardive dyskinesia. J Clin Psych. 2020;81(2):19cs12983. doi: 10.1080/ 14737175.2017.1358616

76. Stacy M, Sajatovic M, Kane JM, et al. Abnormal Involuntary Movement Scale in tardive dyskinesia: minimal clinically important difference. Mov Disord. 2019;34:1203-9.

77. Dedic N, Jones PG, Hopkins SC, et al. SEP-363856, a novel psychotropic agent with a unique, non-D2 receptor mechanism of action. J Pharmacol Exp Ther. 2019;371:1-14. 